\title{
The association of venous developmental anomalies and cavernous malformations: pathophysiological, diagnostic, and surgical considerations
}

\author{
Paolo Perrini, M.D., and Giuseppe Lanzino, M.D. \\ Neurosurgical Department, University of Florence, Italy; and Department of Neurosurgery, Illinois \\ Neurological Institute, University of Illinois College of Medicine at Peoria, Illinois
}

\begin{abstract}
$\checkmark$ Developmental venous anomalies (DVAs) are often associated with intracranial cavernous malformations (CMs). The frequency of this association and the observation of de novo CMs located near a known, preexisting DVA raise speculations as to the possible etiopathogenetic relationship between the two. In this article, the authors review the recent literature dealing with the potential etiopathogenetic, prognostic, and therapeutic implications of the association between DVAs and CMs.
\end{abstract}

\section{KEY WORDS - cavernous malformation - developmental venous anomaly • venous infarction}

I NTRACRANIAL vascular malformations were originally classified by McCormick ${ }^{31}$ into four types: discrete venous, arteriovenous, capillary, and CMs, each with distinct pathological criteria for definition. The range of imaging characteristics and clinical manifestations that generally differentiate them have been characterized in several studies. Recently, mixed or transitional vascular malformations with pathological features of more than one type of malformation within the same lesion have been described. The detection of a wide spectrum of intermediate forms of McCormick's original categories suggests that these lesions might be a continuum of progression of a single pathological process. Investigators have described the simultaneous occurrence of venous malformations and CMs, ${ }^{8,11,13,27,36,41,44}$ arteriovenous and venous malformations, ${ }^{16,19,20,33} \mathrm{CMs}$ with arteriovenous or capillary components, ${ }^{25,34,47}$ and capillary telangiectasias associated with venous malformations. ${ }^{30,45}$ In addition, authors have described venous malformations associated with both a CM and a capillary telangiectasia.,11 The coexistence of a CM and a DVA is the most common mixed vascular malformation. ${ }^{44}$ The natural history of this mixed phenotype is unclear, making it difficult to determine a long-term prognosis for symptomatic and asymptomatic patients. Moreover, much controversy exists about the biological behavior and the management of the DVAs associated with the CM. Even though most authors agree that microsurgical resection of the $\mathrm{CM}$ alone provides protection against future bleeding, ${ }^{35-37,40}$ some reports raise the question whether the abnormal draining vein is the actual area of disease that induces the blood flow disturbances, which in turn result in the formation of a CM (de novo and recurrent). ${ }^{4,10,47,48}$

\footnotetext{
Abbreviations used in this paper: $\mathrm{CM}=$ cavernous malforma-
} tion; DVA = developmental venous anomaly; $\mathrm{MR}=$ magnetic resonance.
In this article, we review the possible pathophysiological implications of the association between CMs and DVAs. We also discuss diagnostic and therapeutic implications of this mixed phenotype.

Prevalence of Associated DVAs and CMs: Diagnostic and Pathological Controversies

Developmental venous anomalies (also referred to as venous malformations, venous angiomas, medullary venous malformations, or caput medusae) are composed of radially arranged medullary veins resembling a "caput medusae" surrounded by normal neural parenchyma and converging in a centrally located dilated trunk. The DVA drains toward either the superficial system or, rarely, the deep venous system; there is no abnormal arteriovenous shunt placement process. Developmental venous anomalies are the most common intracranial vascular malformation, accounting for more than $60 \%$ of all intracranial vascular lesions. ${ }^{29}$ They are encountered in up to $2.5 \%$ of autopsy cases, ${ }^{39}$ although MR imaging-based studies have indicated a much lower incidence ranging from 0.14 to $0.7 \% .^{44,46}$ Much discrepancy exists in the literature concerning the prevalence of the coexistence of CMs and DVAs. Since the first description in 1974 by Roberson, et al. ${ }^{38}$ of an association between a DVA and a CM, authors of several subsequent series have stressed this association. $1,2,4,35,46,48,49$ Based on findings from MR imaging studies, Abdulrauf, et al., ${ }^{1}$ identified 13 (24\%) of 55 patients with CMs who had associated DVAs. A similar percentage was reported by Wurm, et al., ${ }^{48}$ who noticed such an association in $15(25.9 \%)$ of 58 patients based on MR imaging and intraoperative findings. In a series of 86 surgically treated patients with brainstem CMs, Porter, et al. ${ }^{35}$ found a DVA intimately associated with each resected CM. These anomalies were defined as "abnormal veins in the resection bed of the cavernous malformation." In 
the same series preoperative MR imaging findings were consistent with the "classic" DVA appearance on 32\% of 73 preoperative MR images and in 14\% of 50 angiographic studies. This observation suggests that the prevalence of associated DVAs may be underestimated even when high-field MR imaging is used, because small venous anomalies not visible on preoperative studies may be noticed in the surgical cavity following resection of the CMs.

Based on the results of digital subtraction angiography, Kamezawa, et al., ${ }^{21}$ characterized venous drainage in patients with CMs into two types: classic venous drainage and atypical venous drainage. They defined atypical venous drainage as occurring when the venous structures had no connection to the transcortical venous system. In their series, high-resolution MR imaging showed a $78.6 \%$ sensitivity for typical venous drainage and only $10 \%$ sensitivity for atypical drainage. These authors suggested that atypical venous drainage (usually underestimated when MR imaging alone without angiography is used in the preoperative evaluation of patients with CMs) may be identical to the abnormal veins observed by Porter and colleagues ${ }^{35}$ during resection of brainstem CMs.

In 2003, Abe, et al.,2 suggested a careful distinction between two different clinical and histological groups of venous malformations: angiographically occult venous malformations containing compactly arranged venous channels with no smooth muscle layer and angiographically detectable DVAs with dilated thin-walled vessels diffusely distributed in the normal white matter. They reported that angiographically occult venous angiomas can be resected without causing morbidity, whereas the removal of DVAs is likely to be followed by brain swelling and hemorrhagic infarction. Authors of recent series, however, have challenged these observations and have suggested that surgical interruption of the draining vein does not necessarily result in brain edema and/or hemorrhagic infarction. ${ }^{26,48}$ To date, no consistent diagnostic criteria are available to predict whether interruption of DVAs associated with CMs will cause perioperative complications.

\section{Does Associated Venous Drainage Affect the Natural History of CMs?}

In general isolated DVAs are benign and the majority remain clinically silent. Although several authors $7,28,39$ have described an aggressive clinical course of DVAs as having a high risk of hemorrhage, most of these studies were conducted before the advent of MR imaging; thus, the existence of small adjacent CMs could not be excluded. More recent clinical observations do not support these earlier reports and the findings indicate an exceedingly low risk of bleeding associated with isolated DVAs (between $0.22^{18}$ and $0.68 \%$ ). ${ }^{32}$ Rigamonti, et al. ${ }^{37}$ reviewed the cases of 30 patients who had DVAs and reported that, in the two patients who underwent surgery for intracranial hemorrhage presumably due to a DVA, a coexistent unsuspected CM was found at surgery. Similarly, in a retrospective study of 67 patients with DVAs, Töpper, et al., ${ }^{44}$ reported that only the five patients who suffered an intracerebral hemorrhage had an associated CM. The current view is that DVAs are benign congenital lesions resulting from failure of normal embryogenesis. ${ }^{5}$ This supposition is substantiated by the presence of DVAs in children, the lack of a mature venous system surrounding these lesions, the angiographic visualization of DVAs during the normal venous phase, and the observation of extensive infarcts in patients in whom the venous drainage system was surgically ligated. . $^{18,36}$

Authors of several reports have characterized the natural history of CMs. Incidental lesions and those discovered during the evaluation of nonspecific symptoms, such as headache, have a low risk of symptomatic hemorrhage ranging from $0.1^{14}$ to $0.6 \%{ }^{23}$ per patient per year. A more aggressive behavior has been observed in younger patients, ${ }^{6}$ in females, ${ }^{3}$ and in patients who have suffered previous hemorrhage. ${ }^{3,23}$ Authors of several reports have suggested that the CMs associated with a DVA have a more aggressive clinical course. . $^{1,410,13,21,48}$ The pathophysiological basis of such a more aggressive clinical course is largely unknown. Little, et al. ${ }^{24}$ have described a physiological communication between CMs and the venous circulation by measuring intraoperative cortical blood flow and intravascular blood pressure in patients with CMs. Sasaki, et al., ${ }^{40}$ reported the intraoperative findings of the coexistence of a CM and a DVA in which they observed several small veins connecting the $\mathrm{CM}$ with the medullary vein. It has been suggested that latent venous hypertension in association with DVAs can predispose CMs to hemorrhage. ${ }^{1}$ In 1999, Abdulrauf, et al., ${ }^{1}$ conducted a retrospective analysis of 55 consecutive patients with CMs and found that $38 \%$ of those with CMs alone presented with hemorrhage as opposed to $62 \%$ of those who harbored CMs associated with DVAs. The incidence of repeated symptomatic hemorrhage was also higher in patients with coexistent lesions than in those without (23\% compared with 9.5\%); however, these differences did not achieve statistical significance due to the small number of cases in the mixed-phenotype group. In their review of 58 patients with CMs, Wurm, et al.. ${ }^{48}$ found that $93.3 \%$ of those harboring an associated DVA had experienced symptomatic hemorrhage, validating the theory that patients with coexistent lesions are more likely to present with symptomatic hemorrhage than are those with CMs alone.

\section{Pathophysiology of Associated DVAs and CMs: de Novo and Recurrent Lesions}

Authors of several studies have suggested that CMs are active lesions with endothelial proliferation and neoangiogenesis and are characterized by dynamic behaviors including enlargement, regression, and de novo formation. ${ }^{12}$, ${ }^{42,43}$ In addition, the association of DVAs and CMs within the same lesion has generated hypotheses about the causation-evolution relationship among different types of malformations. ${ }^{4}$ It has been postulated that abnormal hemodynamics of venous malformations might induce the formation of CMs. ${ }^{4,10,37}$ Awad, et al., ${ }^{4}$ suggested that the abnormal vascular beds of DVAs may induce hemodynamic disturbance (venous hypertension) or may be fragile enough to cause microhemorrhage that in turn might cause reactive angiogenesis with new vessel formation and coalescence. Such a process has been described as "hemorrhagic angiogenic proliferation." Alternatively, DVA-related venous outflow restriction and venous overload may open preexisting arteriovenous connections, resulting in 
tiny arteriovenous fistulas that can enlarge over time. ${ }^{47}$ Finally, it has been suggested that chronically increased intraluminal pressure and resultant reduced tissue perfusion leading to tissue hypoxia may stimulate a local increase in angiogenic factors inducing the formation of vascular malformations. ${ }^{47}$ Accordingly, Dillon ${ }^{15}$ documented elevated venous pressure within a hemorrhagic DVA with highgrade angiographic stenosis, confirming the hemorrhagic role of venous hypertension.

In 1992, Wilson ${ }^{47}$ described three potential causes of transient, sustained pressure elevation within a venous malformation or its distal radicles. First, sustained elevated venous pressure may be caused by outflow restriction at the site at which the trunk of venous malformation enters the central vein or the venous sinus as described by Dillon. ${ }^{15}$ In addition progressive venous overload and hypertension can also be caused by an acute increase in intracranial venous pressure that in turn is transmitted unimpeded through the radicles of venous malformation. Finally, partial thrombosis within the collector portion of a venous malformation may lead to local increase in venous pressure in the territory deprived of its normal venous drainage. Based on these potential causes, venous malformations can be considered the primary congenital lesion when there are mixed vascular malformations in the region, and venous hypertension can be regarded as the initial pathophysiological factor leading to the formation of CMs and, in rare instances, the formation of a capillary telangectasia. De novo development of a CM has been documented at a rate of 0.36 new lesions per patient per year in familial forms. ${ }^{51}$ Few nonfamilial cases of de novo CMs have been described, usually at the site of the distal radicles of a preexisting DVA. ${ }^{8-10,15}$ Maeder, et al., ${ }^{27}$ reported the de novo appearance of a CM associated with a DVA that developed in a young boy after he underwent radiation therapy for a medulloblastoma. The occurrence of de novo lesions after radiotherapy supports the hypothesis of hemorrhagic angiogenic proliferation. In fact, it has been shown that vessels treated with radiotherapy exhibit hyalinization and fibrinoid necrosis, narrowing of the lumen, and endothelial proliferation. These changes mostly occur on the venous side where veins are dilated and occluded. ${ }^{17}$ In addition, vessels are more friable and prone to leakage of blood products, leading to diapedetic microhemorrhage with reactive angiogenesis, new vessel formations, and coalescence. In 2005, Wurm, et al., ${ }^{48}$ reported three recurrent lesions in 15 surgically treated patients who harbored associated DVAs and CMs in whom the large draining vein of the venous malformation was left untouched during previous interventions. It is worth noting that histopathological analysis revealed that the new lesions were different in nature (three arteriovenous angiomas in two patients and a capillary telangectasia in one patient). These findings support the concept that DVAs can be regarded as the primary lesion leading to the occurrence of mixed vascular malformations, and they suggest a continuum of progression of a single pathological process.

\section{Surgical Treatment of Associated Venous and Cavernous Malformations}

In patients with CMs associated with DVAs it is recommended that every attempt is made to spare the DVA to avoid the risk of venous infarction. ${ }^{35-37,40}$ The prevailing opinion is that the DVA represents an anomalous venous drainage of otherwise normal brain tissue. ${ }^{36}$ If the main trunk is resected, venous engorgement and cerebral edema can result, at times with devastating consequences. ${ }^{35}$ In 1999 , Porter and coworkers ${ }^{35}$ in their series of surgically treated brainstem cavernomas reported one postoperative death due to a cerebellar hemorrhagic infarction related to surgical compromise of the associated DVA. In addition, nonhemorrhagic infarction has been reported after spontaneous thrombosis of a venous malformation, validating the concept that venous anomalies are essential for the drainage from normal brain tissue. ${ }^{22}$ Authors of some surgical reports, however, have challenged this prevalent thinking, describing significant operative treatment of DVAs. ${ }^{26,28,50}$ On the basis of histological findings of surgical specimens, Yamada, et al., ${ }^{50}$ defined the venous malformations that can be safely resected as "pericapillary arteriovenous malformations." In a recent provocative report, Wurm and coworkers ${ }^{48}$ proposed the coagulation and division of the transcerebral vein of the DVA to prevent recurrence of CMs. In their series of 15 patients with DVAs and CMs, they resected the CM and divided the transcerebral vein of the DVA in nine patients-in six during the first operation and in the remaining three patients after recurrence of the associated CM with symptomatic hemorrhage. They observed no brain swelling intraoperatively, and the postoperative course was uneventful in all nine patients. Although we do not recommend dividing the transcerebral vein of associated venous malformation, we think that further investigation into the issue of DVAs associated with CMs is warranted to improve our understanding of the pathophysiology of CMs. It cannot be excluded that by treating the CM we are treating the result of the so-called "hemorrhagic angiogenic proliferation" and not the disease itself, which may indeed be the DVA.

\section{References}

1. Abdulrauf SI, Kaynar MY, Awad IA: A comparison of the clinical profile of cavernous malformations with and without associated venous malformations. Neurosurgery 44:41-47, 1999

2. Abe M, Hagihara N, Tabuchi K, Uchino A, Miyasaka Y: Histologically classified venous angiomas of the brain: a controversy. Neurol Med Chir (Tokyo) 43:1-11, 2003

3. Aiba T, Tanaka R, Koike T, Kameyama S, Takeda N, Komata T: Natural history of intracranial cavernous malformations. J Neurosurg 83:56-59, 1995

4. Awad IA, Robinson JR Jr, Mohanty S, Estes ML: Mixed vascular malformations of the brain: clinical and pathogenetic considerations. Neurosurgery 33:179-188, 1993

5. Awad IA, Spetzler RF, Hodak JA, Awad CA, Carey R: Incidental subcortical lesions identified on magnetic resonance imaging in the elderly. I. Correlation with age and cerebrovascular risk factors. Stroke 17:1084-1089, 1986

6. Barker FG II, Amin-Hanjani S, Butler WE, Lyons S, Ojemann RG, Chapman PH, et al: Temporal clustering of hemorrhages from untreated cavernous malformations of the central nervous system. Neurosurgery 49:15-25, 2001

7. Cabanes J, Blasco R, Garcia M, Tamarit L: Cerebral venous angiomas. Surg Neurol 11:385-389, 1979

8. Cakirer S: De novo formation of a cavernous malformation of the brain in the presence of a developmental venous anomaly. Clin Radiol 58:251-256, 2003

9. Campeau NG, Lane JI: De novo development of a lesion with the appearance of a cavernous malformation adjacent to an existing developmental venous anomaly. AJNR Am J Neuroradiol 26:156-159, 2005 
10. Ciricillo SF, Dillon WP, Fink ME, Edwards MS: Progression of multiple cryptic vascular malformations associated with anomalous venous drainage. Case report. J Neurosurg 81:477-481, 1994

11. Clatterbuck RE, Elmaci I, Rigamonti D: The juxtaposition of a capillary telangiectasia, cavernous malformation, and developmental venous anomaly in the brainstem of a single patient: case report. Neurosurgery 49:1246-1250, 2001

12. Clatterbuck RE, Moriarity JL, Elmaci I, Lee RR, Breiter SN, Rigamonti D: Dynamic nature of cavernous maformations: a prospective magnetic resonance imaging study with volumetric analysis. J Neurosurg 93:981-986, 2000

13. Comey CH, Kondziolka D, Yonas H: Regional parenchymal enhancement with mixed cavernous/venous malformations of the brain. Case report. J Neurosurg 86:155-158, 1997

14. Del Curling O Jr, Kelly DL Jr, Elster AD, Craven TE: An analysis of the natural history of cavernous angiomas. J Neurosurg 75:702-708, 1991

15. Dillon WP: Cryptic vascular malformations: controversies in terminology, diagnosis, pathophysiology, and treatment. AJNR Am J Neuroradiol 18: 1839-1846, 1997

16. Fierstien SB, Pribram HW, Hieshima G: Angiography and computed tomography in the evaluation of cerebral venous malformations. Neuroradiology 17:137-148, 1979

17. Gaensler EHL, Dillon WP, Edwards MS, Larson DA, Rosenau W, Wilson CB: Radiation-induced telangectasia in the brain simulates cryptic vascular malformations at MR imaging. Radiology 193:629-636, 1994

18. Garner TB, Del Curling O Jr, Kelly DL Jr, Laster DW: The natural history of intracranial venous angiomas. J Neurosurg 75: 715-722, 1991

19. Hirata Y, Matsukado Y, Nagahiro S, Kuratsu J: Intracerebral venous angioma with arterial blood supply: a mixed angioma. Surg Neurol 25:227-232, 1986

20. Hirsh LF: Combined cavernous-arteriovenous malformation. Surg Neurol 16:135-139, 1981

21. Kamezawa T, Hamada JI, Niiro M, Kai Y, Ishimaru K, Kuratsu JI: Clinical implications of associated venous drainage in patients with cavernous malformation. J Neurosurg 102:24-28, 2005

22. Konan AV, Raymond J, Bourgouin P, Lesage J, Milot G, Roy D: Cerebellar infarct caused by spontaneous thrombosis of a developmental venous anomaly of the posterior fossa. AJNR Am J Neuroradiol 20:256-258, 1999

23. Kondziolka D, Lunsford LD, Kestle JRW: The natural history of cerebral cavernous malformations. J Neurosurg 83:820-824, 1995

24. Little JR, Awad IA, Jones SC, Ebrahim ZY: Vascula pressures and cortical blood flow in cavernous angioma of the brain. $\mathbf{J}$ Neurosurg 73:555-559, 1990

25. Lobato RD, Rivas JJ, Gomez PA, Cabrera A, Sarabia R, Lamas E: Comparison of the clinical presentation of symptomatic arteriovenous malformations (angiographically visualized) and occult vascular malformations. Neurosurgery 31:391-397, 1992

26. Lupret V, Negovetic L, Smiljanic D, Klanfar Z, Lambasa S: Cerebral venous angiomas: surgery as a mode of treatment for selected cases. Acta Neurochir (Wien) 120:33-39, 1993

27. Maeder P, Gudinchet F, Meuli R, de Tribolet N: Development of a cavernous malformation of the brain. AJNR Am J Neuroradiol 19:1141-1143, 1998

28. Malik GM, Morgan JK, Boulos RS, Ausman JI: Venous angiomas: an underestimated cause of intracranial hemorrhage. Surg Neurol 30:350-358, 1988

29. Martin NA, Wilson CB, Stein BM: Venous and cavernous malformations, in Wilson CB, Stein BM (eds): Intracranial Arteriovenous Malformations. Baltimore: Williams \& Wilkins, 1984, pp 234-245

30. McCormick PW, Spetzler RF, Johnson PC, Drayer BP: Cerebellar hemorrhage associated with capillary telangiectasia and venous angioma: a case report. Surg Neurol 39:451-457, 1993

31. McCormick WF: The pathology of vascular ("arteriovenous") malformations. J Neurosurg 24:807-816, 1966

32. McLaughlin MR, Kondziolka D, Flickinger JC, Lunsford S,
Lunsford LD: The prospective natural history of cerebral venous malformations. Neurosurgery 43:195-201, 1998

33. Numaguchi Y, Kitamura K, Fukui M, Ikeda J, Hasuo K, Kishikawa T, et al: Intracranial venous angiomas. Surg Neurol 18: 193-202, 1982

34. Ogilvy CS, Heros RC, Ojemann RG, New PF: Angiographically occult arteriovenous malformations. J Neurosurg 69: 350-355, 1988 [Erratum in J Neurosurg 70:293, 1989]

35. Porter RW, Detwiler PW, Spetzler RF, Lawton MT, Baskin JJ, Derksen PT, et al: Cavernous malformations of the brainstem: experience with 100 patients. J Neurosurg 90:50-58, 1999

36. Rigamonti D, Spetzler RF: The association of venous and cavernous malformations. Report of four cases and discussion of the pathophysiological, diagnostic, and therapeutic implications. Acta Neurochir (Wien) 92:100-105, 1988

37. Rigamonti D, Spetzler RF, Medina M, Rigamonti K, Geckle DS, Pappas C: Cerebral venous malformations. J Neurosurg 73:560-564, 1990

38. Roberson GH, Kase CS, Wolpow ER: Teleangiectases and cavernous angiomas of the brainstem: "cryptic" vascular malformations. Report of a case. Neuroradiology 8:83-89, 1974

39. Sarwar M, McCormick WF: Intracerebral venous angioma. Case report and review. Arch Neurol 35:323-325, 1978

40. Sasaki O, Tanaka R, Koike T, Koide A, Koizumi T, Ogawa H: Excision of cavernous angioma with preservation of coexisting venous angioma. Case report. J Neurosurg 75:461-464, 1991

41. Sheehan J, Lunsford LD, Kondziolka D, Flickinger J: Development of a posterior fossa cavernous malformation associated with bilateral venous anomalies: case report. J Neuroimaging 12:371-373, 2002

42. Sure U, Butz N, Schlegel J, Siegel AM, Wakat JP, Mennel HD, et al: Endothelial proliferation, neoangiogenesis, and potential de novo generation of cerebrovascular malformations. J Neurosurg 94:972-977, 2001

43. Sure U, Freman S, Bozinov O, Benes L, Siegel AM, Bertalanffy $\mathrm{H}$ : Biological activity of adult cavernous malformations: a study of 56 patients. J Neurosurg 102:342-347, 2005

44. Töpper R, Jürgens E, Reul J, Thron A: Clinical significance of intracranial developmental venous anomalies. J Neurol Neurosurg Psychiatry 67:234-238, 1999

45. Van Roost D, Kristof R, Wolf HK, Keller E: Intracerebral capillary telangiectasia and venous malformation: a rare association. Surg Neurol 48:175-183, 1997

46. Wilms G, Bleus E, Demaerel P, Marchal G, Plets C, Goffin J, et al: Simultaneous occurrence of developmental venous anomalies and cavernous angiomas. AJNR Am J Neuroradiol 15:1247-1257, 1994

47. Wilson CB: Cryptic vascular malformations. Clin Neurosurg 38:49-84, 1992

48. Wurm G, Schnizer M, Fellner FA: Cerebral cavernous malformations associated with venous anomalies: surgical considerations. Neurosurgery 57 (1 Suppl):S42-S58, 2005

49. Wurm G, Schnizer M, Nussbaumer K, Wies W, Holl K: Recurrent cryptic vascular malformation associated with a developmental venous anomaly. Br J Neurosurg 17:188-195, 2003

50. Yamada S, Liwnicz BH, Thompson JR, Colohan ART, Iacono RP, Tran JT: Pericapillary arteriovenous malformations angiographically manifested as cerebral venous malformations. Neurol Res 23:513-521, 2001

51. Zabramski JM, Wascher TM, Spetzler RF, Johnson B, Golfinos J, Drayer BP, et al: The natural history of familial cavernous malformations: results of an ongoing study. J Neurosurg 80: 422-432, 1994

Manuscript received May 19, 2006.

Accepted in final form May 30, 2006.

Address reprint requests to: Giuseppe Lanzino, M.D., Department of Neurosurgery, University of Illinois College of Medicine at Peoria, 530 Glen Oak Avenue, Peoria, Illinois 61637. email: lanzino@uic.edu. 